\title{
Posterior thoracic corpectomy with cage reconstruction for metastatic spinal tumors: comparing the mini-open approach to the open approach
}

\author{
Darryl Lau, MD, and Dean Chou, MD \\ Department of Neurological Surgery, University of California, San Francisco, California
}

\begin{abstract}
OBJECT Spinal metastases most commonly affect the vertebral bodies of the spinal column, and spinal cord compression is an indication for surgery. Commonly, an open posterior approach is employed to perform a transpedicular costotransversectomy or lateral extracavitary corpectomy. Because of the short life expectancies in patients with metastatic spinal disease, decreasing the morbidity of surgical treatment and recovery time is critical. One potential approach to decreasing morbidity is utilizing minimally invasive surgery (MIS). Although significant advances have been made in MIS of the spine, data supporting the utility of MIS are still emerging. This study compared outcomes of patients who underwent mini-open versus traditional open transpedicular corpectomy for spinal metastases in the thoracic spine.
\end{abstract}

METHODS A consecutive cohort from 2006 to 2013 of 49 adult patients who underwent thoracic transpedicular corpectomies for spinal metastases was retrospectively identified. Patients were categorized into one of 2 groups: open surgery and mini-open surgery. Mini-open transpedicular corpectomy was performed with a midline facial incision over only the corpectomy level of interest and percutaneous instrumentation above and below that level. The open procedure consisted of a traditional posterior transpedicular corpectomy. Chi-square test, 2-tailed t-test, and ANOVA models were employed to compare perioperative and follow-up outcomes between the 2 groups.

RESULTS In the analysis, there were 21 patients who had mini-open surgery and 28 patients who had open surgery. The mean age was 57.9 years, and $59.2 \%$ were male. The tumor types encountered were lung $(18.3 \%)$, renal/bladder $(16.3 \%)$, breast $(14.3 \%)$, hematological $(14.3 \%)$, gastrointestinal tract $(10.2 \%)$, prostate $(8.2 \%)$, melanoma $(4.1 \%)$, and other/unknown (14.3\%). There were no significant intergroup differences in demographics, comorbidities, neurological status (American Spinal Injury Association [ASIA] grade), number of corpectomies performed, and number of levels instrumented. The open group had a mean operative time of 413.6 minutes, and the mini-open group had a mean operative time of 452.4 minutes $(p=0.329)$. Compared with the open group, the mini-open group had significantly less blood loss ( $917.7 \mathrm{ml}$ vs $1697.3 \mathrm{ml}, p=0.019$ ) and a significantly shorter hospital stay (7.4 days vs 11.4 days, $p=0.001)$. There was a trend toward a lower perioperative complication rate in the mini-open group $(9.5 \%)$ compared with the open group $(21.4 \%)$, but this was not statistically significant $(p=0.265)$. At follow-up, there were no significant differences in ASIA grade $(p=0.342)$, complication rate after the 30 -day postoperative period $(p=0.999)$, or need for surgical revision $(p=$ 0.803 ). The open approach had a higher overall infection rate of $17.9 \%$ compared with that in the mini-open approach of $9.5 \%$, but this was not statistically significant $(p=0.409)$.

CONCLUSIONS The mini-open transpedicular corpectomy is associated with less blood loss and shorter hospital stay compared with open transpedicular corpectomy. The mini-open corpectomy also trended toward lower infection and complication rates, but these did not reach statistical significance.

http://thejns.org/doi/abs/10.3171/2014.12.SPINE14543

KEY WORDS corpectomy; metastatic spine tumor; minimally invasive; mini-open; transpedicular; thoracic; expandable cage; oncology

ABBREVIATIONS AP = anterior-posterior; ASIA = American Spinal Injury Association; EBL = estimated blood loss; $\mathrm{MIS}=$ minimally invasive surgery; $\mathrm{PE}=$ pulmonary embolus; pRBCs $=$ packed red blood cells.

SUBMITTED June 1, 2014. ACCEPTED December 3, 2014.

INCLUDE WHEN CITING Published online May 1, 2015; DOI: 10.3171/2014.12.SPINE14543.

DISCLOSURE Dr. Chou has received honoraria from Globus, Medtronic, DePuy, and Orthofix for teaching. No funding was provided for this study. Otherwise, the authors report no conflict of interest concerning the materials or methods used in this study or the findings specified in this paper. 
$\mathrm{T}$ HE incidence of spinal metastases is on the rise because patients are living longer as a result of more effective anticancer therapies. ${ }^{22}$ Spinal metastases most commonly affect the vertebral bodies of the spinal column and can lead to vertebral body destruction, causing spinal cord compression or spinal instability. ${ }^{45}$ In such cases, surgical intervention is warranted, and the goals of surgery are to decompress the spinal cord, facilitate local disease control (if possible), and stabilize the spine. ${ }^{5,44} \mathrm{~A}$ corpectomy of the thoracolumbar spine can be performed through an anterior-only approach, a posterior-only approach, or an anterior-posterior (AP) approach. ${ }^{35,48}$ Some surgeons prefer to use posterior-only approaches (such as costotransversectomy, transpedicular corpectomy, or lateral extracavitary) to perform thoracic corpectomy. ${ }^{14,15,31,35,46}$ This is because posterior-only approaches avoid the morbidity of the anterior approach and obviate the need for an access surgeon. ${ }^{21,26,31,35}$ In addition, posterior-only approaches treat multiple spinal levels and AP pathology all in a single-stage surgery. ${ }^{31}$

Posterior-only thoracic corpectomies are thought to be associated with less morbidity than the AP approaches. ${ }^{21,26,31,35}$ However, they are commonly performed through a traditional open approach, with large exposures, requiring significant muscle and fascial dissection over several spinal levels for instrumentation and for access to the anterior spine. 7,14,19,31,35 Therefore, substantial blood loss, long recovery time, and relatively high rates of complications continue to be unfavorable issues. ${ }^{31,35}$ Minimizing morbidity and shortening recovery time are important in all patients, but even more so in patients with spinal metastasis because of limited life spans. One potential approach to decreasing morbidity is utilizing minimally invasive surgery (MIS).

The origins of MIS in spine procedures stem from the utilization of tubular retractors via small skin incisions. Often, pathological lesions are readily accessed through a posterior or posterolateral approach. However, the locations of metastatic tumors are quite variable and often affect the anterior spinal elements, such as the vertebral body. The location of the tumor may also involve the posterior elements or be localized laterally to one side. Because of this variability, docking a table-mounted retractor at a standard docking point based upon anatomical landmarks may not be ideal; rather, tumor bulk and areas of cord compression generally dictate surgical approach, not standard anatomical landmarks as for degenerative cases. This makes the use of a standard, constant docking point and a tablemounted retractor less viable. To overcome this limitation, mini-open hybrid approaches to the spine have been adapted to minimize soft-tissue damage, yet still perform the same operation as in the open case. Mini-open approaches have been used to perform corpectomies, vertebral column resections, and correction for spinal deformity in the thora-

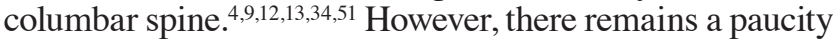
of studies that have evaluated the outcomes of the miniopen posterior corpectomy and the traditional open posterior corpectomy of the thoracic spine. In this study, we compare outcomes of patients who underwent mini-open versus those who underwent open transpedicular corpectomy for metastasis in the thoracic spine.

\section{Methods}

This study was formally approved by the University of California, San Francisco, Committee for Human Research.

\section{Patients}

All patients who underwent a single-stage posterior transpedicular corpectomy by the senior author (D.C.) were retrospectively identified. The study period of interest was from 2006 to 2013. Inclusion criteria were patients who were 18 years or older, underwent a complete posterior-approach transpedicular corpectomy with expandable cage reconstruction of the anterior spinal column, and had surgery for metastatic tumor. Patients who were younger than 18 years and/or who had other diagnoses were excluded from the study. Diagnosis of metastasis was confirmed through histopathological analysis performed on intraoperatively obtained specimens. Patients who had met the Patchell criteria underwent surgery. ${ }^{44}$ Other indications for surgery were spinal instability, failure of medical or radiation therapy in patients with cord compression, or radioresistant tumors causing cord compression. Prior to surgery, oncological prognosis was taken into account in the decision of whether surgical intervention was warranted. Patients who underwent surgery for hematological malignancies underwent surgery for neurological deficits secondary to cord compression with an unknown diagnosis prior to surgery or had nondiagnostic biopsies.

\section{Selection for Open Versus Mini-Open Transpedicular Corpectomy}

Patients underwent either open or mini-open surgery based on availability of operating room staff and equipment. For instance, if surgery could be started during normal work hours, a mini-open approach was performed, even if the case was emergent. However, if surgery had to be done outside normal work hours (nights) or on weekends, when regular spine operating room personnel, MIS screw systems, or navigation support was not available, the traditional open procedure was performed. The senior surgeon (D.C.) performed all the operations in this study, regardless of the time of surgery.

\section{Mini-Open Transpedicular Corpectomy and Percutaneous Pedicle Fixation}

A detailed description of the mini-open transpedicular corpectomy has been described previously. ${ }^{13}$ In brief, the patient was placed prone onto a Jackson table. The skin was opened at the midline, but the fascia was preserved (Fig. 1). Pedicle screw fixation was performed utilizing a percutaneous pedicle screw fixation system. The percutaneous screws were placed transfascially in the same manner that they are placed percutaneously. If fluoroscopy was used, we first placed Jamshidi needles into the pedicles using AP and lateral fluoroscopy. K-wires were then placed into the pedicles. The fascia was opened over each K-wire with a No. 15 scalpel blade to accommodate the screws. A tap was then placed over the K-wires, the tap was removed, and the screws were placed under fluoroscopic guidance. The K-wires were subsequently removed. If 

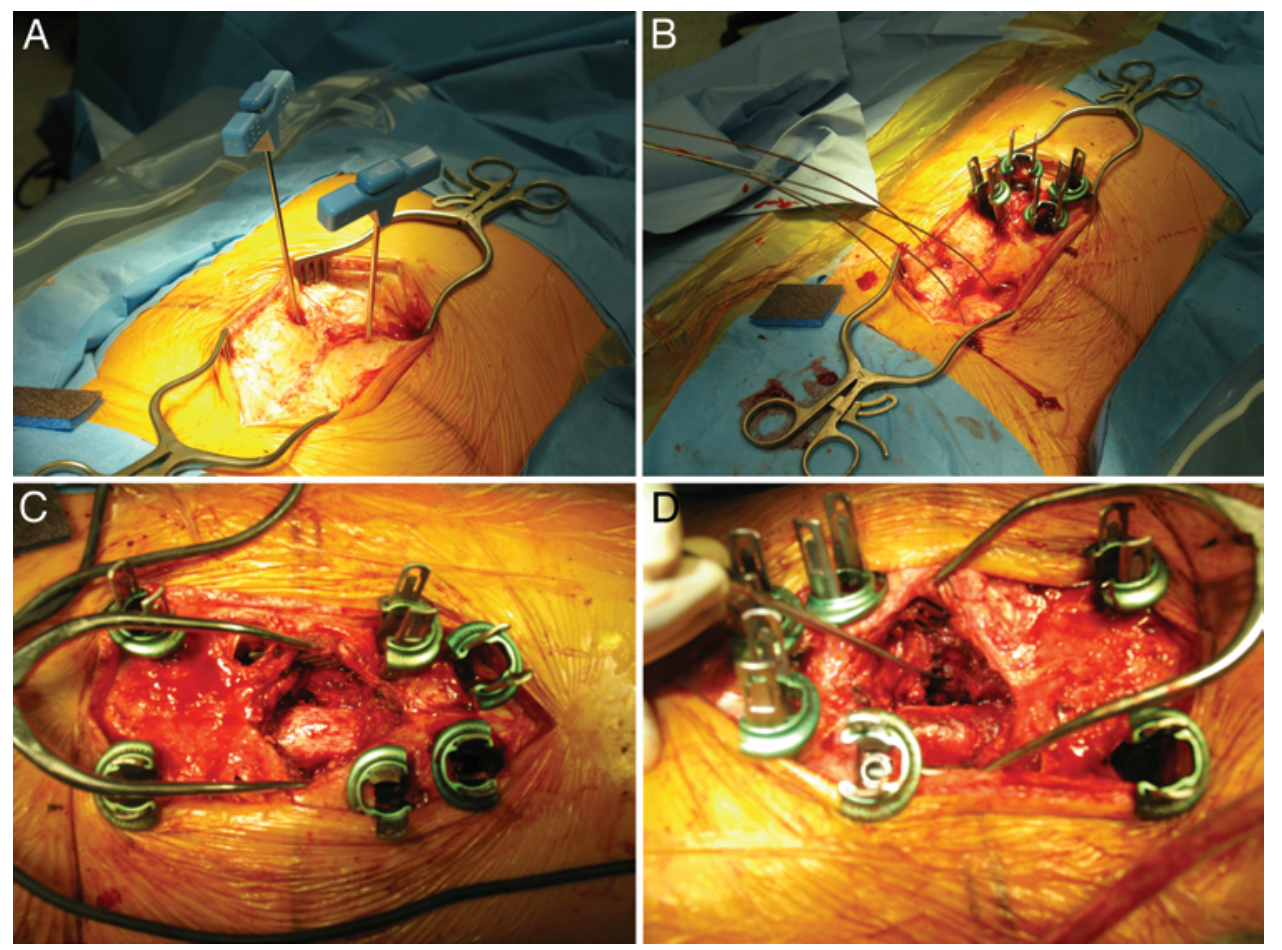

FIG. 1. Part 1: Intraoperative photographs of the mini-open technique. A: Midline incision of skin and subcutaneous tissue, with preservation of fascia and paraspinal muscles. Cannulation of pedicles with Jamshidi needles. B: Rostral percutaneous pedicle screw placement and K-wires marking pedicles caudal to the corpectomy level. C: Mini-opening of corpectomy site, exposing fascia and muscle only at the level of interest, and completion of laminectomy. Two of the screw extenders have been temporarily removed to facilitate the corpectomy. D: Trap-door rib head osteotomy completed. Figure is available in color online only.

navigation was used, the screws were placed transfascially through a single skin incision using navigated drills, taps, and screws. A confirmatory intraoperative CT scan was obtained in cases requiring navigation to confirm placement of the screws, whereas AP and lateral fluoroscopy was used to confirm screw position in fluoroscopy-based cases.

At the level where corpectomy was performed, the fascia was opened over the vertebral body that harbored tumor and half of the superior and inferior lamina. The fascia was held open using a self-retaining retractor, and laminectomy was performed. A temporary rod was placed, the transpedicular corpectomy was performed, and the discs and posterior longitudinal ligament were then removed. A trap-door rib head osteotomy was performed to mobilize the rib, and the rib head was then separated from the vertebral body. ${ }^{11,14}$ An expandable titanium cage was used to reconstruct the anterior spinal column in all cases. The cage was placed as ventrally as possible to rest on the anterior apophyseal ring of the vertebral body (Fig. 2). Arthrodesis was performed only over the level of corpectomy, anteriorly and posteriorly. No arthrodesis was attempted at the levels of percutaneous instrumentation above and below the corpectomy site. A case example is seen in Fig. 3, and an artist's illustration of the mini-open and open surgeries is shown in Fig. 4.

\section{Data}

The electronic medical records were retrospectively reviewed for data collection. Demographic and baseline clinical information were collected for age (years), sex, weight $(\mathrm{kg})$, presence of comorbidities (chronic obstructive pulmonary disease, heart disease, cerebrovascular accident/transient ischemia attack, kidney disease, liver disease, diabetes mellitus, hypertension), neurological deficit/ spinal cord injury, and presence of extraspinal metastasis. Spinal cord function was based on the patient's neurological examination findings and was scored utilizing the American Spinal Injury Association (ASIA) scale. ${ }^{37}$ Operative data collected included number of contiguous corpectomies performed, number of levels instrumented, and graft type used (autograft, allograft, or mix of autograft and allograft).

Perioperative outcomes of interest included operative time, estimated blood loss (EBL), need for blood transfusion, complications, and length of stay. Operative time was defined as the time from incision to time of incision closure and was reported in minutes. EBL was recorded in milliliters. The need for a blood transfusion intraoperatively and/ or during the postoperative course was recorded. In addition, the volume of packed red blood cells (pRBCs) was totaled. Perioperative complications were defined as any unexpected event requiring additional medical or surgical intervention within 30 days of surgery. Length of stay was defined as days spent in the hospital, from day of surgery to day of discharge. Follow-up outcomes of interest were complications after the 30-day perioperative period, need for reoperation, and neurological status measured via ASIA grade (A to E). Follow-up of less than 6 months was deemed as lost to follow-up. Change in neurological status 

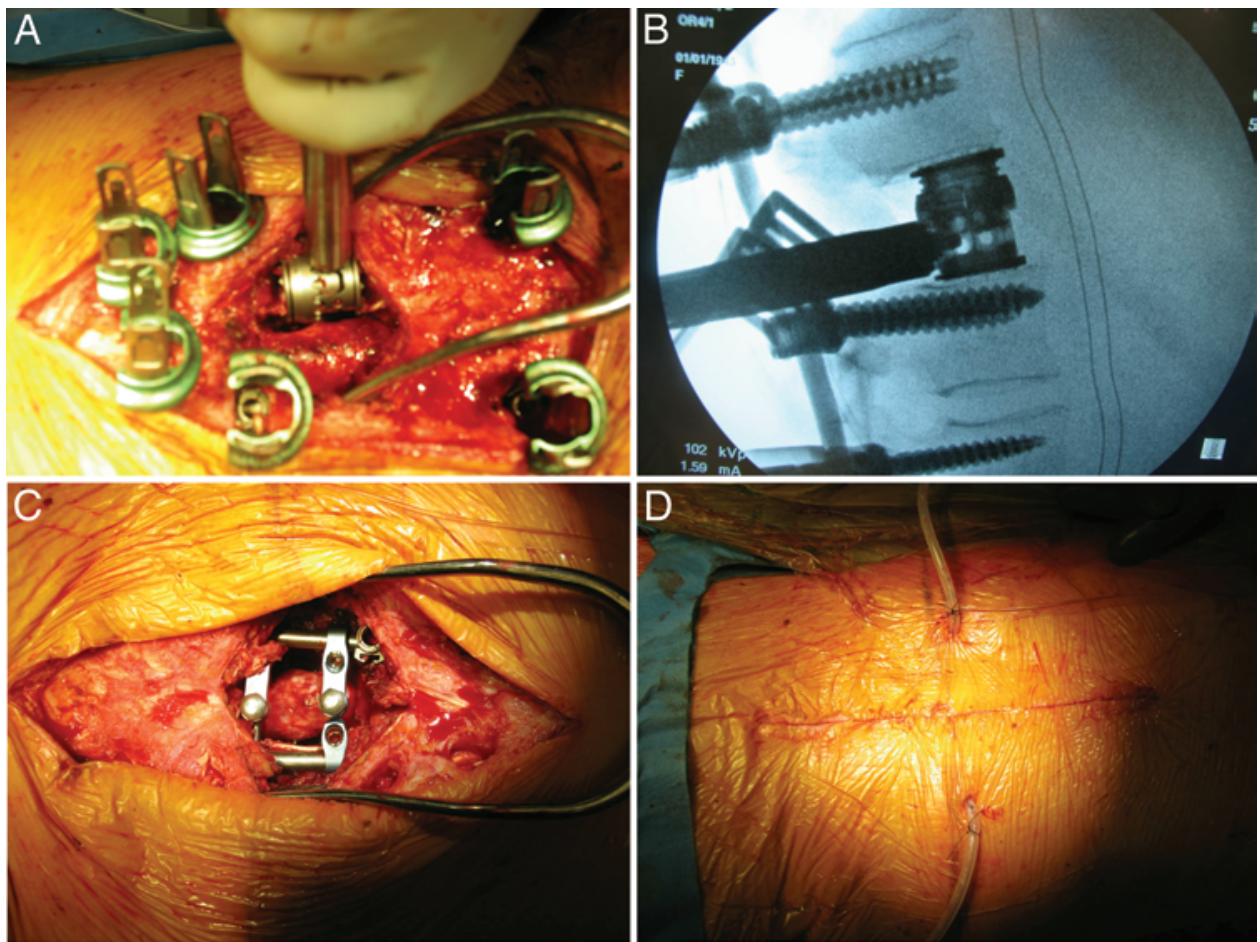

FIG. 2. Part 2: Intraoperative photographs of the mini-open corpectomy. A: After completion of the corpectomy, an expandable cage is placed. B: Lateral fluoroscopic film confirming placement of the expandable cage. C: Rods are then locked into placed and cross-links are placed for increased stability. D: Closure of linear skin incision. Figure is available in color online only.

was categorized as improved, stable, or worsened based upon whether the ASIA grade changed after surgery.

\section{Statistical Analysis}

Surgeries were categorized into one of 2 groups based upon the approach for the transpedicular corpectomy: open or mini-open. Descriptive statistics were performed to summarize the findings. Bivariate comparative analysis of outcomes between the 2 groups was performed. Chisquare test for categorical variables/outcomes was used. Two-tailed Student t-test and ANOVA for continuous variable/outcomes were used. A p value of 0.050 was used as the threshold for statistical significance. All statistical analysis was performed with SAS 9.3 (SAS Institute).

\section{Results}

In the period of interest, a total of 27 patients underwent a mini-open transpedicular corpectomy, with 21 having the diagnosis of metastatic tumor; 6 patients with nonmetastatic diagnoses were excluded from this study. During the same cohort period, 28 patients underwent an open transpedicular corpectomy for metastatic cancer to the thoracic spine. Therefore, 49 patients were included in the final analysis: 28 patients in the open group and 21 in the miniopen group. Of the 49 patients, 35 patients had follow-up greater than 6 months (21 in the open group and 14 in the mini-open group). Among the 14 patients missing followup, 10 patients died prior to the 6-month follow-up, and 4 patients resumed their care elsewhere. The mean follow-up duration among the 35 patients was 15.4 months.

Demographic information and baseline characteristics of the patients included in this study are presented in Table 1. In the open surgery group, the mean age was 59.5 years and $64.3 \%$ were male. In the mini-open group, the mean age was 55.8 years and $52.4 \%$ were male. The 2 groups were well matched and demonstrated similar demographics and baseline clinical characteristics. There were no significant intergroup differences in age, sex, weight, comorbidities, ASIA grade, tumor type, or presence of extraspinal metastasis. A variety of tumor types were encountered: lung (18.3\%), renal/bladder (16.3\%), breast (14.3\%), hematological (14.3\%), gastrointestinal tract $(10.2 \%)$, prostate $(8.2 \%)$, melanoma (4.1\%), and other/unknown (14.3\%).

Table 2 compares perioperative variables and outcomes between the open and mini-open groups. Overall, most patients underwent a 1-level corpectomy (79.6\%), 16.3\% underwent a 2-level corpectomy, and $4.1 \%$ underwent a corpectomy of 3 or more levels. There was no significant difference in the number of contiguous corpectomies performed between the 2 groups $(\mathrm{p}=0.413$ ). Most patients in the open and mini-open group underwent 1-level corpectomy (75.0\% vs $85.7 \%$, respectively). There was no significant difference in the median number of levels instrumented $(6$ in the open vs 5 in the mini-open, $p=0.292$ ). More patients in the mini-open group received allograft for fusion material $(71.4 \%)$ than in the open group (39.3\%), but this was not statistically significant ( $\mathrm{p}=0.062$ ). In the mini-open group, 4 patients $(19.0 \%)$ underwent iliac crest grafting and 2 patients $(9.5 \%)$ underwent local bone autografting (away from tumor). In the open group, 5 patients (17.9\%) received an iliac crest bone autograft and 11 patients (39.3\%) received a local bone autograft (distant from tumor).

Overall mean EBL for both cohorts was $1362.8 \mathrm{ml}$, 

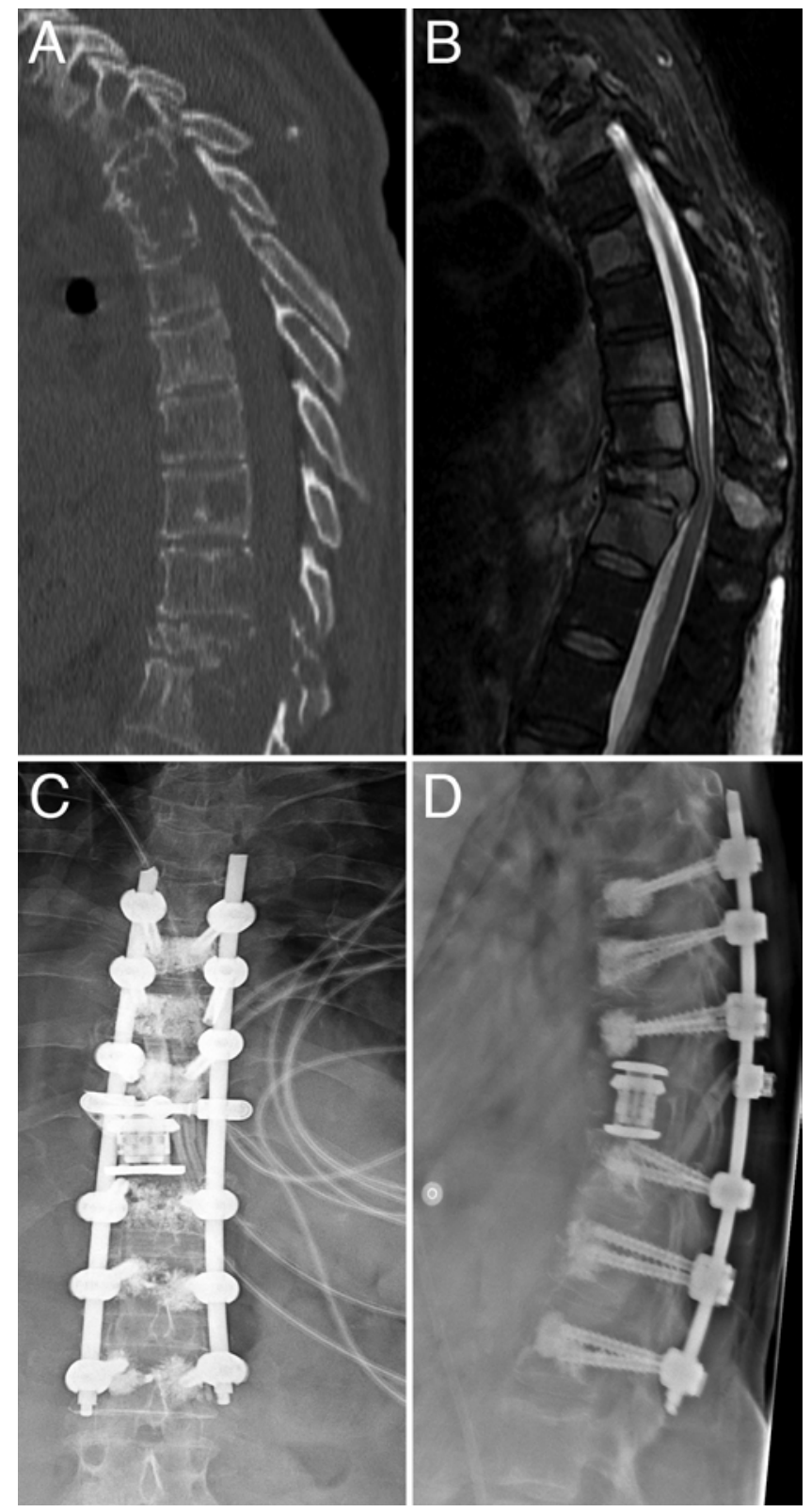

FIG. 3. Lower thoracic metastasis of breast origin treated with miniopen transpedicular corpectomy and percutaneous instrumentation. A: Sagittal noncontrast CT scan of the thoracic spine showing pathological fracture at T-10 and multiple lytic lesions secondary to diffuse spinal metastasis. B: Sagittal T2-weighted MR image showing severe spinal cord compression at T-10. Postoperative AP (C) and lateral (D) radiographs demonstrating a T-10 mini-open corpectomy, reconstruction with an expandable cage, and instrumented fusion at T-7 to L-1 with methylmethacrylate augmentation.

and the mean hospital stay was 9.7 days (Table 2). The mini-open group had significantly less mean EBL (916.7 $\mathrm{ml}$, range 300-1900 $\mathrm{ml}$ ) compared with the open group (1697.3 ml, range 350-3250 ml) $(\mathrm{p}=0.019)$ (Fig. 5). Table 3 lists vascular tumor types and their associated blood losses, stratified by approach. A total of 6 cases $(12.2 \%)$ of renal cell carcinoma were treated; there was no significant difference in the incidence of renal cell carcinoma between the open and mini-open group (14.3\% vs 9.5\%) (p
$=0.615)$. Of the 49 cases, $8.2 \%$ were treated for melanoma. All melanoma cases were in the mini-open group and made up $19.0 \%$ of the mini-open cases, and this difference was significant $(0.0 \%$ vs $19.0 \%)(p=0.016)$. Among the whole cohort, there was 1 case of thyroid adenocarcinoma $(2.0 \%)$, and for this tumor type there was no significant difference in incidence between the open and mini-open group $(0.0 \%$ vs $4.8 \%)(\mathrm{p}=0.243)$.

Of the 49 patients, $61.2 \%$ required at least 1 blood transfusion during their perioperative course and a mean of 3.0 units of pRBCs was transfused (Table 2). There was no significant difference in the rate of blood transfusion between the open and mini-open group $(64.3 \%$ vs $57.1 \%$, respectively) $(\mathrm{p}=0.611)$. However, there was a significant difference in the amount of $\mathrm{pRBCs}$ transfused ( $\mathrm{p}=$ 0.050 ). The mini-open group required a mean of 2.1 units of $\mathrm{pRBCs}$ and the open group required a mean of 3.6 units of pRBCs.

Taken together, the overall mean operative time for the 2 groups was 424.4 minutes (Table 2). The open group had a mean operative time of 413.6 minutes, and the miniopen group had an operative time of 452.4 minutes $(\mathrm{p}=$ 0.329 ). The mini-open group had a significantly shorter mean hospital stay than the open group (mean 7.4 days, median 6 days, range 4-21 days vs mean 11.4 days, median 11 days, range 5-20 days, respectively) $(p=0.001)$ (Fig. 5). There was a tendency toward higher perioperative complication rates in the open group compared with the mini-open group (21.4\% vs $9.5 \%$, respectively), but this did not reach statistical significance $(p=0.265)$. Perioperative complications encountered in the open group included wound infections in 3 patients ( 2 requiring washout); epidural hematoma requiring interventional radiology drainage in 1 patient; a postoperative fluid collection requiring reoperation in 1 patient; and deep vein thrombosis, pulmonary embolus (PE), and sepsis in 1 patient. In the mini-open group, 1 patient experienced a wound infection and 1 patient developed a PE.

Figure 5 shows the overall infection rate during the perioperative and follow-up periods. The open group had higher infection rates, but the difference was not statistically significant $(\mathrm{p}=0.409)$. The overall infection rate was $17.9 \%$ in the open group and $9.5 \%$ in the mini-open group. When stratified by period, the perioperative infection rate was $10.7 \%$ in the open group and $4.8 \%$ in the mini-open group, and the follow-up infection rate was $7.2 \%$ in the open group and $4.8 \%$ in the mini-open group.

Table 4 shows the outcome end points at follow-up after the 30-day perioperative period. Of the 35 patients, $14.3 \%$ experienced complications after the perioperative period. Both the open and mini-open group each had follow-up complication rates of $14.3 \%$ ( $\mathrm{p}=0.999)$. Overall, $8.6 \%$ of patients required reoperation. Reoperation rates were similar between the open group $(9.5 \%)$ and the mini-open group $(7.1 \%)(p=0.803)$. In the open group, 1 patient underwent reoperation for pseudarthrosis, and 1 patient underwent reoperation for wound dehiscence with exposed hardware. One patient in the mini-open group underwent reoperation for wound dehiscence. There was no significant difference in ASIA grade at follow-up, with most patients maintaining Grades $\mathrm{D}$ and $\mathrm{E}$ in both groups $(\mathrm{p}=0.342)$. Changes 


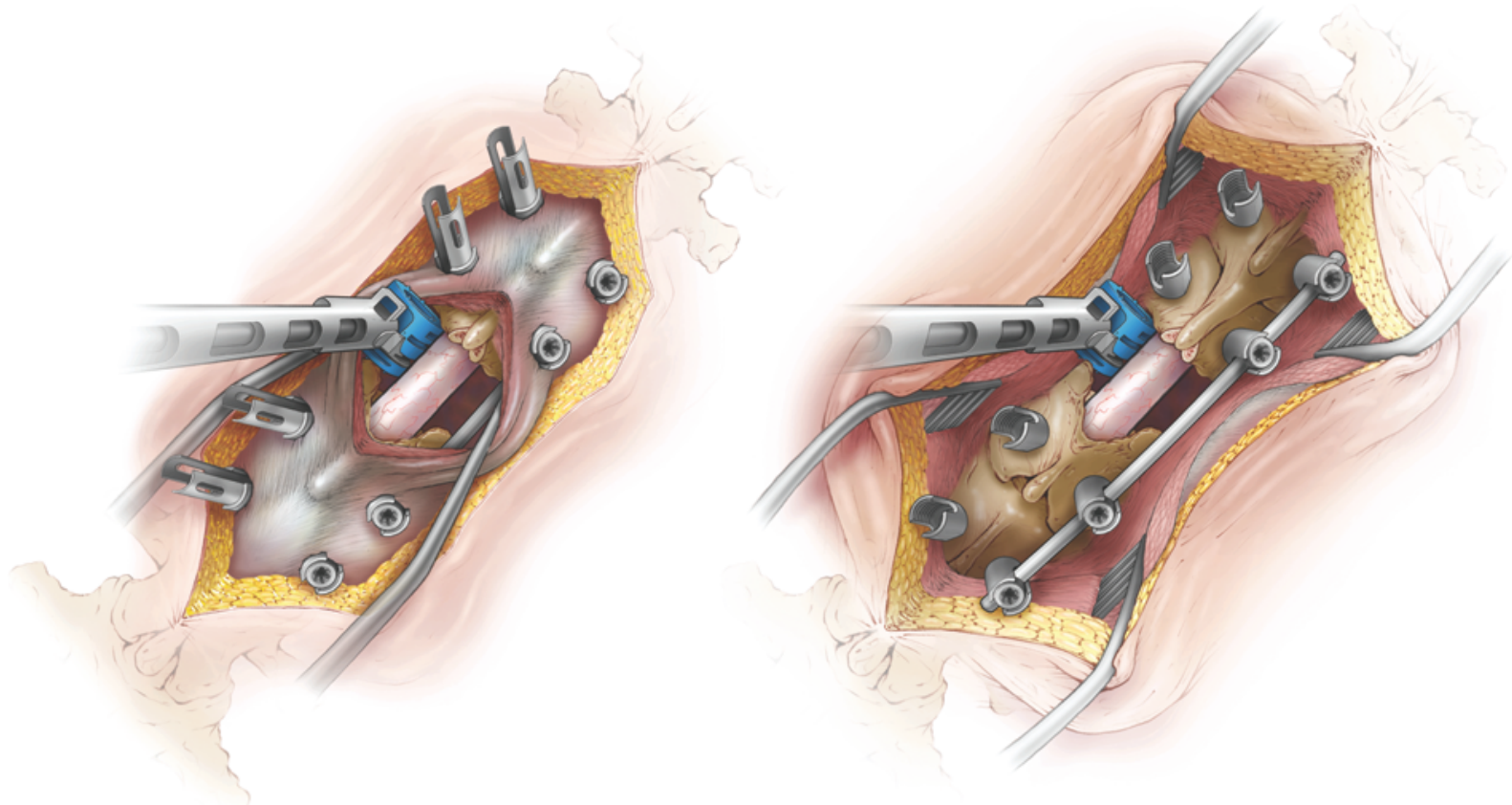

FIG. 4. Artist's illustrations of the mini-open and open transpedicular corpectomy demonstrating the same skin incision, but the soft-tissue dissection differs between the 2 techniques. Copyright Dean Chou. Published with permission. Figure is available in color online only.

in ASIA grade were also similar at follow-up $(\mathrm{p}=0.999)$ : improvement (open, $42.9 \%$ vs mini-open, $42.9 \%$ ) and no change (open, $57.1 \%$ vs mini-open, $57.1 \%$ ).

Clinical follow-up included plain radiographs, but since most patients did not undergo significant deformity correction, kyphosis and lordosis were not specifically measured.

\section{Discussion}

Because the overall goal of surgery for spinal metastases is to improve quality of life, it is important to minimize the morbidity of surgery and shorten recovery time. ${ }^{29,44}$ Traditionally, corpectomies of the thoracolumbar spine are performed via anterior approaches, posterior approaches, or AP approaches. ${ }^{14,15,31,35,46,48}$ When posterior-based corpectomies are performed in the traditional open fashion, large incisions with extensive stripping of the paraspinal muscles can occur. ${ }^{7,14,19,31,35}$ The morbidity and complication rates can be as high as $50 \%-60 \%$, and recovery time can be extensive. . $^{18,25,27}$

Over the past decade, there has been a movement toward the utilization of less invasive approaches to spine surgery because MIS has been shown to yield less blood loss, shorter hospitalization, and lower infection rates than open approaches. . $^{828,30,43}$ The findings from this study suggest that the mini-open transpedicular corpectomy with anterior column reconstruction offers advantages over the traditional open posterior corpectomy. The mini-open approach resulted in less blood loss and a shorter hospital stay. There was also a tendency toward a lower perioperative complication rate and infection rate with the miniopen approach. In addition, patients who underwent the mini-open approach achieved the same neurological outcome as patients who underwent the open approach.
Most studies of MIS of the spine have focused on the treatment of degenerative spinal disorders, but there are a few papers describing the use of MIS for spinal tumors. However, they mostly concentrate on benign nerve sheath tumors or intradural tumors. In addition, there is a paucity of comparative studies, and most studies involve small cohorts. Nonetheless, the overall outcomes are quite promising. Nzokou et al. retrospectively reviewed their experience with minimally invasive removal of extradural foraminal and intradural extramedullary tumors using nonexpandable tubular retractors in 13 patients. ${ }^{41}$ With their technique, they achieved gross-total resection in 12 of the 13 patients and had no complications. Similarly, Lu et al. retrospectively compared the results of a traditional open approach (in 9 patients) and those of a mini-open approach (in 18 patients) for resection of intradural spinal tumors. ${ }^{34}$ Mini-open resections resulted in less blood loss and a shorter hospital stay. After total resection, there were no recurrences in either cohort. The most common tumors encountered in these 2 studies were meningiomas, schwannomas, and ependymomas..$^{34,41}$ The location in which these intradural tumors arose (usually within the spinal canal) is very different from that of most spinal metastases (mainly in the vertebral body). Therefore, technical considerations can be quite variable when treating spinal column metastases.

Many studies of MIS for spinal metastases focus on anterior approaches to the anterior spinal column, but these approaches often rely on a second-stage posterior stabilization procedure. ${ }^{39}$ There have been technical reports and cadaver studies of MIS posterior-only corpectomies, but there are few clinical reports of utilizing the technique in the treatment for spinal metastasis. ${ }^{36,40}$ Taghva et al. re- 
TABLE 1. Comparison of demographics, comorbidities, and baseline clinical variables in patients who underwent open and mini-open transpedicular corpectomy for thoracic spinal metastasis

\begin{tabular}{lllll}
\hline Baseline Characteristics & $\begin{array}{c}\text { Total } \\
(\mathrm{n}=49)\end{array}$ & $\begin{array}{c}\text { Open } \\
(\mathrm{n}=28)\end{array}$ & $\begin{array}{c}\text { Mini-Open } \\
(\mathrm{n}=21)\end{array}$ & $\begin{array}{c}\mathrm{p} \\
\text { Value }\end{array}$ \\
\hline Age (yrs) & 57.9 & 59.5 & 55.8 & 0.363 \\
\hline Male sex (\% male) & $29(59.2)$ & $18(64.3)$ & $11(52.4)$ & 0.401 \\
\hline Weight (kg) & 70.9 & 71.3 & 70.4 & 0.845 \\
\hline Comorbidities (\%) & & & & \\
\hline COPD & $0(0.0)$ & $0(0.0)$ & $0(0.0)$ & 0.999 \\
\hline Heart disease & $3(6.1)$ & $3(10.7)$ & $0(0.0)$ & 0.122 \\
\hline TIA/CVA & $1(2.0)$ & $1(3.6)$ & $0(0.0)$ & 0.382 \\
\hline Kidney disease & $2(4.1)$ & $1(3.6)$ & $1(4.8)$ & 0.835 \\
\hline Liver disease & $4(8.2)$ & $2(7.1)$ & $2(9.5)$ & 0.763 \\
\hline Diabetes & $4(8.2)$ & $3(10.7)$ & $1(4.8)$ & 0.451 \\
\hline Hypertension & $14(28.6)$ & $10(35.7)$ & $4(19.1)$ & 0.201 \\
\hline ASIA grade (\%) & & & & 0.662 \\
\hline E & $19(38.8)$ & $10(35.7)$ & $9(42.9)$ & \\
\hline D & $20(40.8)$ & $12(42.9)$ & $8(38.1)$ & \\
\hline C & $8(16.3)$ & $5(17.9)$ & $3(14.3)$ & \\
\hline B & $1(2.0)$ & $0(0.0)$ & $1(4.8)$ & \\
\hline A & $1(2.0)$ & $1(3.6)$ & $0(0.0)$ & \\
\hline Tumor origin (\%) & & & & 0.100 \\
\hline Lung & $9(18.4)$ & $6(21.4)$ & $3(14.3)$ & \\
\hline Renal/bladder & $8(16.3)$ & $6(21.4)$ & $2(9.5)$ & \\
\hline Breast & $7(14.3)$ & $2(7.1)$ & $5(23.8)$ & \\
\hline Hematological & $7(14.3)$ & $6(21.4)$ & $1(4.8)$ & \\
\hline Gastrointestinal tract & $5(10.2)$ & $2(7.1)$ & $3(14.3)$ & \\
\hline Prostate & $4(8.2)$ & $0(0.0)$ & $4(19.1)$ & \\
\hline Melanoma & $2(4.1)$ & $1(3.6)$ & $1(4.8)$ & \\
\hline Unknown & $7(14.3)$ & $5(17.9)$ & $2(9.5)$ & \\
\hline Extraspinal metastasis & $19(38.8)$ & $10(35.7)$ & $9(42.9)$ & 0.612 \\
\hline
\end{tabular}

COPD = chronic obstructive pulmonary disease $; C V A=$ cardiovascular ac cident; TIA = transient ischemic attack.

ported the use of MIS via expandable tubular retractors in the treatment of a 36-year-old man with metastatic lung adenocarcinoma to the spine. ${ }^{49}$ The patient underwent a 2-level vertebrectomy at T-4 and T-5 and anterior column reconstruction with an expandable cage placed using bilateral expandable tubular retractors and percutaneous instrumented fusion from T-1 to T-8. The difference between their method and the one we describe in our study is the use of a bilateral rather than a single posterior approach. Zairi et al. prospectively evaluated 10 patients who underwent minimally invasive partial vertebrectomy and percutaneous instrumentation for thoracolumbar spinal metastasis. ${ }^{54}$ Their outcomes were quite promising, with mean operative times of only 170 minutes, mean EBL of $400 \mathrm{ml}$, and no perioperative complications. However, their study involved no reconstruction of the anterior spinal column, which is very different from the patients in our series, who all underwent expandable cage reconstruction. The treatment concept in their study is similar to "separation surgery," in which circumferential spinal cord decompression and separation of the thecal sac from the epidural tumor is achieved to optimize radiation therapy. ${ }^{3,32}$ In the study by Laufer et al., dorsal separation and decompression were done via laminectomy, facetectomy, and/or partial tumor resection. ${ }^{32}$ Ventral separation and decompression were done via tumor resection and limited vertebral body resection. The reported outcomes for this technique are promising, especially in patients at higher risk for invasive surgery, but complete corpectomy was not performed nor was anterior column reconstruction. Moreover, separation surgery relies heavily on stereotactic radiosurgery, and this treatment modality may not be available at all hospitals. ${ }^{32}$

Although some MIS techniques have evolved into miniopen approaches, the benefits appear to be similar, and the working corridor may provide more flexibility than true MIS surgery. The observed benefits of the mini-open approach over the traditional open approach are similar to those of prior studies of small-incision MIS: less muscle injury, less blood loss, shorter hospital stay, and lower rates of infection. ${ }^{17,33,50}$ To our knowledge, there are no studies comparing the posterior-based mini-open corpectomy with cage reconstruction to the traditional open approach for spinal metastases. Among studies addressing spinal metastases, we found only 1 small case series utilizing a mini-open lateral approach and 2 individual case reports of a posterior-based mini-open approach to corpectomy for spinal metastasis. ${ }^{9,12,52}$ Although other techniques have been described, many are not true posterior-only approaches or do not incorporate reconstruction of the anterior spinal column as we did in our series. Given the paucity of reports and absence of studies regarding the mini-open or MIS posterior corpectomies, direct detailed comparisons of our findings with historical controls are not possible.

The findings from this study suggest that the mini-open approach is associated with less blood loss than the traditional open transpedicular corpectomy. The difference in the EBL may be multifactorial. The open approach requires at least 4-6 additional levels of fascial opening and muscle dissection compared with the mini-open approach (depending on whether fixation is 3 levels above/below or 2 levels above/below). Greater fascial and muscle opening leads to more bleeding points. The blood loss does not occur just during exposure, but there tends to be gradual bleeding - especially with any coagulopathy or thrombocytopenia that ensues-with exposed muscle and tissue. However, even though the fascial opening in the miniopen procedure is smaller, this alone may not necessarily account for the 800-ml difference in EBL between the groups. In our cohort, there may have been a component of a slight bias toward more renal cell carcinoma tumor types in the open group, contributing to higher blood loss. Even though the difference in renal cell carcinoma tumor types was not statistically significant, the study may be underpowered to detect a difference. Another consideration is that the mini-open group had more vascular tumors, even though there were fewer renal cell carcinoma cases in the mini-open group. 
TABLE 2. Comparison of perioperative outcomes of patients who underwent open and mini-open transpedicular corpectomy for thoracic spinal metastasis*

\begin{tabular}{|c|c|c|c|c|}
\hline Perioperative Outcomes & Total $(n=49)$ & Open $(n=28)$ & Mini-Open $(n=21)$ & $\mathrm{p}$ Value \\
\hline No. of corpectomies (\%) & & & & 0.413 \\
\hline 1 & $39(79.6)$ & $21(75.0)$ & $18(85.7)$ & \\
\hline 2 & $8(16.3)$ & $5(17.9)$ & $3(14.3)$ & \\
\hline 3 or more & $2(4.1)$ & $2(7.1)$ & $0(0.0)$ & \\
\hline Levels of fusion (median) & 6 & 6 & 5 & 0.292 \\
\hline Graft type (\%) & & & & 0.062 \\
\hline Autograft & $16(32.7)$ & $11(39.3)$ & $5(23.8)$ & \\
\hline Allograft & $26(53.1)$ & $11(39.3)$ & $15(71.4)$ & \\
\hline Both & $7(14.3)$ & $6(21.4)$ & $1(4.8)$ & \\
\hline $\mathrm{EBL}(\mathrm{ml})$ & 1362.8 & 1697.3 & 916.7 & 0.019 \\
\hline \multicolumn{5}{|l|}{ Blood transfusion } \\
\hline No. of patients (\%) & $30(61.2)$ & $18(64.3)$ & $12(57.1)$ & 0.611 \\
\hline Amount of pRBCs (no.)† & 3.0 & 3.6 & 2.1 & 0.050 \\
\hline Operative time (mins) & 424.4 & 413.6 & 452.4 & 0.329 \\
\hline Length of stay (days) & 9.7 & 11.4 & 7.4 & 0.001 \\
\hline Complication (\%) & $8(16.3)$ & $6(21.4)$ & $2(9.5)$ & 0.265 \\
\hline Mortality $(\%)$ & $0(0.0)$ & $0(0.0)$ & $0(0.0)$ & 0.999 \\
\hline
\end{tabular}

Because EBL is only an estimation, blood loss in the mini-open approach from the transmuscle insertion of percutaneous pedicle screws may not be readily accounted for in EBL. Transfusion data, an indirect reflection of blood loss and anemia, are helpful in determining whether the mini-open approach results in less blood loss. The findings from this study suggest that the mini-open approach is associated with a transfusion rate similar to that for the open approach, but the mini-open approach offers benefits of requiring fewer blood products. These findings are important because multiple studies have shown that greater numbers of perioperative blood transfusions in cancer patients are associated with increased rates of 30-day peri- operative mortality, higher rates of major complications (such as deep vein thrombosis/PE), and prolonged length of stay. ${ }^{2,53}$ In addition, a randomized prospective study of patients undergoing curative resection for colorectal cancer found that perioperative allogeneic blood transfusion was independently associated with tumor recurrence (relative risk of 6.18). ${ }^{23}$

The average length of stay for our whole cohort was 9.7 days. Review of cases with long hospital stays in both open and mini-open groups indicated that those patients were in the hospital for various reasons such as stabilization of medical comorbidities, management of complications, and completion of oncological workup for metastatic disease.
A

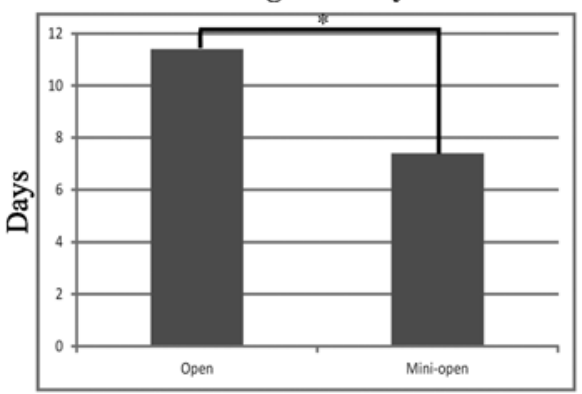

Approach
B

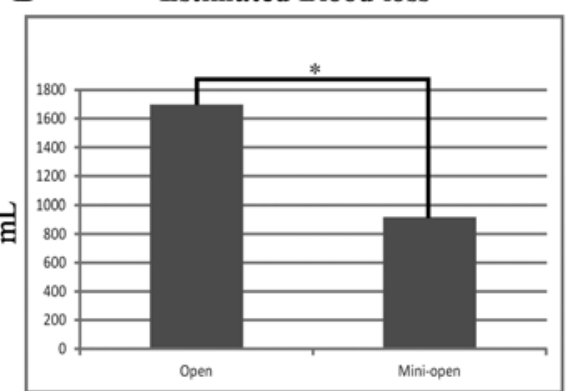

Approach

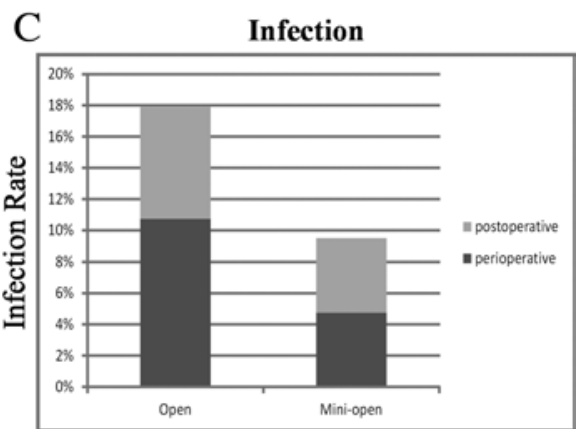

Approach

FIG. 5. Blood loss (A), length of stay (B), and infectious complication rates (C) in patients who underwent open and mini-open transpedicular corpectomy. Asterisk indicates statistical significance $(p<0.05)$. The mean EBL was significantly less in the mini-open group of patients $(916.7 \mathrm{ml})$ than in the open surgery group of patients $(1697.3 \mathrm{ml})(p=0.019)$. A significantly shorter mean hospital stay was also noted in the mini-open group compared with the open group (7.4 days vs 11.4 days, respectively) ( $p=$ 0.001). The open approach was associated with a higher infection rate (17.9\%) than the mini-open approach $(9.5 \%)$, and infections occurred more often in both the perioperative (10.7\% vs $4.8 \%$ ) and follow-up period ( $7.2 \%$ vs $4.8 \%$ ), but these differences were not statistically significant $(p=0.409)$. 
TABLE 3. Vascular tumor types and associated blood loss

\begin{tabular}{|c|c|c|c|c|}
\hline Vascular Tumor Types & Total $(n=49)$ & Open $(n=28)$ & Mini-Open $(n=21)$ & p Value \\
\hline Renal cell carcinoma (\%) & $6(12.2)$ & $4(14.3)$ & $2(9.5)$ & 0.615 \\
\hline Mean EBL (ml) & 1875.0 & 2037.5 & 1550.0 & 0.518 \\
\hline Individual EBL (ml)* & & $1200,3250,2000,1700$ & 1900,1200 & \\
\hline Melanoma (\%) & $4(8.2)$ & $0(0.0)$ & $4(19.0)$ & 0.016 \\
\hline Mean EBL (ml) & 725.0 & NA & 725.0 & NA \\
\hline Individual EBL (ml) ${ }^{*}$ & & & $500,1000,900,500$ & \\
\hline Thyroid adenocarcinoma (\%) & $1(2.0)$ & $0(0.0)$ & $1(4.8)$ & 0.243 \\
\hline Mean EBL (ml) & 500.0 & NA & 500.0 & NA \\
\hline Individual EBL $(\mathrm{ml})^{*}$ & & & 500 & \\
\hline All vascular tumors (\%) & $11(22.4)$ & $4(14.3)$ & $7(33.3)$ & 0.114 \\
\hline Mean EBL (ml) & 1331.8 & 2037.5 & 928.6 & \\
\hline
\end{tabular}

Several patients treated in this cohort presented without prior cancer diagnosis, and spinal metastasis was their first presentation of metastatic disease requiring extensive oncological workup and staging.

The length of stay for patients who underwent the open transpedicular corpectomy was about 11 days; this is similar to the lengths of stay reported in the literature following open corpectomy for spinal metastasis (10-12 days) $)^{20,24,42}$ and modified costotransversectomy for various thoracic vertebral pathologies (16.2 days). ${ }^{31}$ Patients who underwent the mini-open transpedicular corpectomy stayed in the hospital for a shorter amount of time (7 days). This indirectly implies that recovery from surgery may be hastened with the mini-open approach. In addition to facilitating patient recovery, a difference of 4 days can also have a significant impact on medical cost. Total direct hospital cost has been shown to be directly proportional to the length of hospital stay, and the marginal cost of an addi-

TABLE 4. Comparison of follow-up outcomes of patients who underwent open and mini-open transpedicular corpectomy for thoracic spinal metastasis*

\begin{tabular}{lcccc}
\hline Follow-Up Outcomes & $\begin{array}{c}\text { Total } \\
(\mathrm{n}=35)\end{array}$ & $\begin{array}{c}\text { Open } \\
(\mathrm{n}=21)\end{array}$ & $\begin{array}{c}\text { Mini-Open } \\
(\mathrm{n}=14)\end{array}$ & $\begin{array}{c}\mathrm{p} \\
\text { Value }\end{array}$ \\
\hline Complication (\%) & $5(14.3)$ & $3(14.3)$ & $2(14.3)$ & 0.999 \\
\hline Revision/reoperation (\%) & $3(8.6)$ & $2(9.5)$ & $1(7.1)$ & 0.803 \\
\hline Follow-up ASIA grade (\%) & & & & 0.342 \\
\hline E & $26(74.3)$ & $17(80.9)$ & $9(64.3)$ & \\
\hline D & $8(22.9)$ & $4(19.1)$ & $4(28.6)$ & \\
\hline C & $1(2.9)$ & $0(0.0)$ & $1(7.1)$ & \\
\hline B & $0(0.0)$ & $0(0.0)$ & $0(0.0)$ & \\
\hline A & $0(0.0)$ & $0(0.0)$ & $0(0.0)$ & \\
\hline ASIA grade change (\%) & & & & 0.999 \\
\hline Improved & $15(42.9)$ & $9(42.9)$ & $6(42.9)$ & \\
\hline No change & $20(51.4)$ & $12(57.1)$ & $8(57.1)$ & \\
\hline Worsened & $0(0.0)$ & $0(0.0)$ & $0(0.0)$ & \\
\hline
\end{tabular}

* Values are presented as the number (\%) of patients. tional day of hospital care following spine surgery ranges from $\$ 1700$ to $\$ 2800 .{ }^{38}$ Theoretically, an additional 4 days in the hospital can cost an extra $\$ 6800$ to $\$ 11,200$. In addition, longer hospital stays place patients at higher risk for a multitude of complications. ${ }^{16}$ One possible reason for the shorter hospital stays for patients who undergo the miniopen corpectomy may be the lower perioperative complication rate in these patients (a difference of $11.9 \%$ between the open and mini-open group), even though this difference is not statistically significant. The observed perioperative complication rate of $9.5 \%$ in the mini-open group is not only lower than the rate for its matched open cohort counterpart, but also much lower than complication rates reported in the literature for open posterior approaches for corpectomy (range 30\%-63\%). ${ }^{1,6,10,18,20,47}$ In addition, less muscle dissection may have resulted in less pain and fostered the patients' ability to mobilize early. Although we did not quantitatively measure pain outcomes in this study, reduced pain may be a reason there is quicker recovery; further studies specifically addressing pain are needed to definitively support this theory, however.

There are limitations to this study. The main drawbacks are related to the retrospective study design and relatively small cohort. The selection of the mini-open approach versus the open approach was based mainly on availability of operating room staff and supplies, and equipment for MIS was not always immediately available. This may have resulted in a selection bias of urgent or emergent cases being performed in an open fashion, and may also be a reason for the increased infection rate seen. Late evening or weekend cases without regular staff may have resulted in a slightly higher infection rate because of the lack of routine. This results in a selection bias. However, having the same surgeon performing the surgery regardless of time and condition likely offsets some of the underlying biases, but a selection bias may nonetheless still affect the results. Another limitation of a retrospective study that directly applies to this study is the lack of quality of life outcomes. Because survival is short for patients with spinal metastasis, understanding whether the mini-open approach offers a higher quality of life than the open approach is 
important. Unfortunately, this study was not prospectively designed to record quality of life end points, and most patients have died; therefore, those data points were unavailable. Inherently, a retrospective design places this particular study at risk for confounder bias. Confounders are difficult to avoid in a retrospective study, but the open and mini-open cohorts appear to be well matched. Smallcohort studies are susceptible to individual outlying data points that can influence the absolute means or rates. However, this study cohort was fairly homogeneous (including only patients with metastatic lesions in the thoracic region who were operated on by a single surgeon), so the risk of outliers was minimized in this subset of patients.

\section{Conclusions}

The mini-open transpedicular corpectomy was associated with less blood loss and a shorter hospital stay than the traditional open corpectomy. Although not statistically significant, the mini-open approach was observed to have lower rates of complications and infections, especially during the perioperative period. The mini-open approach is a valid alternative to open corpectomy and may result in less blood loss and shorter hospital stay in patients with metastatic spine tumors. However, the selection bias in this study of open cases being done more emergently and miniopen cases being done electively should be taken into consideration when drawing conclusions about the difference.

\section{Acknowledgments}

We would like to thank Frank Fitzgerald for his ideas, encouragement, and contributions to this technique. We would like to thank Ken Probst for his artistic contribution to this manuscript.

\section{References}

1. Akeyson EW, McCutcheon IE: Single-stage posterior vertebrectomy and replacement combined with posterior instrumentation for spinal metastasis. J Neurosurg 85:211-220, 1996

2. Al-Refaie WB, Parsons HM, Markin A, Abrams J, Habermann EB: Blood transfusion and cancer surgery outcomes: a continued reason for concern. Surgery 152:344-354, 2012

3. Amankulor NM, Xu R, Iorgulescu JB, Chapman T, Reiner AS, Riedel E, et al: The incidence and patterns of hardware failure after separation surgery in patients with spinal metastatic tumors. Spine J 14:1850-1859, 2014

4. Amin BY, Tu TH, Mummaneni PV: Mini-open transforaminal lumbar interbody fusion. Neurosurg Focus 35 (2 Suppl):Video 2, 2013

5. Bhatt AD, Schuler JC, Boakye M, Woo SY: Current and emerging concepts in non-invasive and minimally invasive management of spine metastasis. Cancer Treat Rev 39:142152,2013

6. Bilsky MH, Boland P, Lis E, Raizer JJ, Healey JH: Singlestage posterolateral transpedicle approach for spondylectomy, epidural decompression, and circumferential fusion of spinal metastases. Spine (Phila Pa 1976) 25:2240-2250, 2000

7. Boachie-Adjei O, Bradford DS: Vertebral column resection and arthrodesis for complex spinal deformities. J Spinal Disord 4:193-202, 1991

8. Brodano GB, Martikos K, Lolli F, Gasbarrini A, Cioni A, Bandiera S, et al: Transforaminal lumbar interbody fusion in degenerative disc disease and spondylolisthesis grade I: minimally invasive versus open surgery. J Spinal Disord Tech [epub ahead of print], 2013
9. Charles YP, Schuller S, Sfeir G, Steib JP: Mini open tumor resection and percutaneous instrumentation for T11 renal cell carcinoma metastasis. Eur Spine J 22:1440-1442, 2013

10. Chen YJ, Hsu HC, Chen KH, Li TC, Lee TS: Transpedicular partial corpectomy without anterior vertebral reconstruction in thoracic spinal metastases. Spine (Phila Pa 1976) 32:E623-E626, 2007

11. Chou D, Eltgroth M, Yang I, Lu D, Manley G: Rib head disarticulation for multilevel transpedicular thoracic corpectomies and expandable cage reconstruction. Neurol India 57:469-474, 2009

12. Chou D, Lau D, Roy E: Feasibility of the mini-open vertebral column resection for severe thoracic kyphosis. J Clin Neurosci 21:841-845, 2013

13. Chou D, Lu DC: Mini-open transpedicular corpectomies with expandable cage reconstruction. Technical note. J Neurosurg Spine 14:71-77, 2011

14. Chou D, Wang VY: Trap-door rib-head osteotomies for posterior placement of expandable cages after transpedicular corpectomy: an alternative to lateral extracavitary and costotransversectomy approaches. J Neurosurg Spine 10:40-45, 2009

15. Chou D, Wang VY, Gupta N: Transpedicular corpectomy with posterior expandable cage placement for L1 burst fracture. J Clin Neurosci 16:1069-1072, 2009

16. Delgado-Rodríguez M, Bueno-Cavanillas A, López-Gigosos R, de Dios Luna-Castillo J, Guillén-Solvas J, Moreno-Abril $\mathrm{O}$, et al: Hospital stay length as an effect modifier of other risk factors for nosocomial infection. Eur J Epidemiol 6:34-39, 1990

17. Dhall SS, Wang MY, Mummaneni PV: Clinical and radiographic comparison of mini-open transforaminal lumbar interbody fusion with open transforaminal lumbar interbody fusion in 42 patients with long-term follow-up. J Neurosurg Spine 9:560-565, 2008

18. Di Martino A, Vincenzi B, Denaro L, Barnaba SA, Papalia $\mathrm{R}$, Santini D, et al: 'Internal bracing' surgery in the management of solid tumor metastases of the thoracic and lumbar spine. Oncol Rep 21:431-435, 2009

19. Fang T, Dong J, Zhou X, McGuire RA Jr, Li X: Comparison of mini-open anterior corpectomy and posterior total en bloc spondylectomy for solitary metastases of the thoracolumbar spine. J Neurosurg Spine 17:271-279, 2012

20. Gokaslan ZL, York JE, Walsh GL, McCutcheon IE, Lang FF, Putnam JB Jr, et al: Transthoracic vertebrectomy for metastatic spinal tumors. J Neurosurg 89:599-609, 1998

21. Han SJ, Lau D, Lu DC, Theodore P, Chou D: Anterior thoracolumbar corpectomies: approach morbidity with and without an access surgeon. Neurosurgery 68:1220-1226, 2011

22. Hayat MJ, Howlader N, Reichman ME, Edwards BK: Cancer statistics, trends, and multiple primary cancer analyses from the Surveillance, Epidemiology, and End Results (SEER) Program. Oncologist 12:20-37, 2007

23. Heiss MM, Mempel W, Delanoff C, Jauch KW, Gabka C, Mempel M, et al: Blood transfusion-modulated tumor recurrence: first results of a randomized study of autologous versus allogeneic blood transfusion in colorectal cancer surgery. $\mathbf{J}$ Clin Oncol 12:1859-1867, 1994

24. Holman PJ, Suki D, McCutcheon I, Wolinsky JP, Rhines LD, Gokaslan ZL: Surgical management of metastatic disease of the lumbar spine: experience with 139 patients. J Neurosurg Spine 2:550-563, 2005

25. Ibrahim A, Crockard A, Antonietti P, Boriani S, Bünger C, Gasbarrini A, et al: Does spinal surgery improve the quality of life for those with extradural (spinal) osseous metastases? An international multicenter prospective observational study of 223 patients. J Neurosurg Spine 8:271-278, 2008

26. Jarrett CD, Heller JG, Tsai L: Anterior exposure of the lumbar spine with and without an "access surgeon": morbidity 
analysis of 265 consecutive cases. J Spinal Disord Tech 22:559-564, 2009

27. King GJ, Kostuik JP, McBroom RJ, Richardson W: Surgical management of metastatic renal carcinoma of the spine. Spine (Phila Pa 1976) 16:265-271, 1991

28. Lau D, Khan A, Terman SW, Yee T, La Marca F, Park P: Comparison of perioperative outcomes following open versus minimally invasive transforaminal lumbar interbody fusion in obese patients. Neurosurg Focus 35(2):E10, 2013

29. Lau D, Leach MR, La Marca F, Park P: Independent predictors of survival and the impact of repeat surgery in patients undergoing surgical treatment of spinal metastasis. J Neurosurg Spine 17:565-576, 2012

30. Lau D, Lee JG, Han SJ, Lu DC, Chou D: Complications and perioperative factors associated with learning the technique of minimally invasive transforaminal lumbar interbody fusion (TLIF). J Clin Neurosci 18:624-627, 2011

31. Lau D, Song Y, Guan Z, Sullivan S, La Marca F, Park P: Perioperative characteristics, complications, and outcomes of single-level versus multilevel thoracic corpectomies via modified costotransversectomy approach. Spine (Phila Pa 1976) 38:523-530, 2013

32. Laufer I, Iorgulescu JB, Chapman T, Lis E, Shi W, Zhang Z, et al: Local disease control for spinal metastases following "separation surgery" and adjuvant hypofractionated or highdose single-fraction stereotactic radiosurgery: outcome analysis in 186 patients. J Neurosurg Spine 18:207-214, 2013

33. Lee DY, Jung TG, Lee SH: Single-level instrumented miniopen transforaminal lumbar interbody fusion in elderly patients. J Neurosurg Spine 9:137-144, 2008

34. Lu DC, Chou D, Mummaneni PV: A comparison of mini-open and open approaches for resection of thoracolumbar intradural spinal tumors. J Neurosurg Spine 14:758-764, 2011

35. Lu DC, Lau D, Lee JG, Chou D: The transpedicular approach compared with the anterior approach: an analysis of 80 thoracolumbar corpectomies. J Neurosurg Spine 12:583-591, 2010

36. Maciejczak A, Barnas P, Dudziak P, Jagiełło-Bajer B, Litwora B, Sumara M: Posterior keyhole corpectomy with percutaneous pedicle screw stabilization in the surgical management of lumbar burst fractures. Neurosurgery 60 (4 Suppl 2):232-242, 2007

37. Maynard FM Jr, Bracken MB, Creasey G, Ditunno JF Jr, Donovan WH, Ducker TB, et al: International standards for neurological and functional classification of spinal cord injury. Spinal Cord 35:266-274, 1997

38. McCarthy IM, Hostin RA, O'Brien MF, Fleming NS, Ogola G, Kudyakov R, et al: Analysis of the direct cost of surgery for four diagnostic categories of adult spinal deformity. Spine J 13:1843-1848, 2013

39. Molina CA, Gokaslan ZL, Sciubba DM: A systematic review of the current role of minimally invasive spine surgery in the management of metastatic spine disease. Int J Surg Oncol 2011:598148, 2011

40. Musacchio M, Patel N, Bagan B, Deutsch H, Vaccaro AR, Ratliff J: Minimally invasive thoracolumbar costotransversectomy and corpectomy via a dual-tube technique: evaluation in a cadaver model. Surg Technol Int 16:221-225, 2007

41. Nzokou A, Weil AG, Shedid D: Minimally invasive removal of thoracic and lumbar spinal tumors using a nonexpandable tubular retractor. J Neurosurg Spine 19:708-715, 2013

42. Onimus M, Papin P, Gangloff S: Results of surgical treatment of spinal thoracic and lumbar metastases. Eur Spine J 5:407-411, 1996
43. Parker SL, Adogwa O, Witham TF, Aaronson OS, Cheng J, McGirt MJ: Post-operative infection after minimally invasive versus open transforaminal lumbar interbody fusion (TLIF): literature review and cost analysis. Minim Invasive Neurosurg 54:33-37, 2011

44. Patchell RA, Tibbs PA, Regine WF, Payne R, Saris S, Kryscio RJ, et al: Direct decompressive surgical resection in the treatment of spinal cord compression caused by metastatic cancer: a randomised trial. Lancet 366:643-648, 2005

45. Sciubba DM, Petteys RJ, Dekutoski MB, Fisher CG, Fehlings MG, Ondra SL, et al: Diagnosis and management of metastatic spine disease. A review. J Neurosurg Spine 13:94108,2010

46. Shen FH, Marks I, Shaffrey C, Ouellet J, Arlet V: The use of an expandable cage for corpectomy reconstruction of vertebral body tumors through a posterior extracavitary approach: a multicenter consecutive case series of prospectively followed patients. Spine J 8:329-339, 2008

47. Sundaresan N, Digiacinto GV, Hughes JE, Cafferty M, Vallejo A: Treatment of neoplastic spinal cord compression: results of a prospective study. Neurosurgery 29:645-650, 1991

48. Sundaresan N, Steinberger AA, Moore F, Sachdev VP, Krol G, Hough L, et al: Indications and results of combined anterior-posterior approaches for spine tumor surgery. J Neurosurg 85:438-446, 1996

49. Taghva A, Li KW, Liu JC, Gokaslan ZL, Hsieh PC: Minimally invasive circumferential spinal decompression and stabilization for symptomatic metastatic spine tumor: technical case report. Neurosurgery 66:E620-E622, 2010

50. Tsutsumimoto T, Shimogata M, Ohta H, Misawa H: Miniopen versus conventional open posterior lumbar interbody fusion for the treatment of lumbar degenerative spondylolisthesis: comparison of paraspinal muscle damage and slip reduction. Spine (Phila Pa 1976) 34:1923-1928, 2009

51. Upadhyaya C, Ziewacs J, Mummaneni P: Mini-open posterior approach for adult deformity correction. Neurosurg Focus 35 (2 Suppl):Video 14, 2013

52. Uribe JS, Dakwar E, Le TV, Christian G, Serrano S, Smith WD: Minimally invasive surgery treatment for thoracic spine tumor removal: a mini-open, lateral approach. Spine (Phila Pa 1976) 35 (26 Suppl):S347-S354, 2010

53. Xenos ES, Vargas HD, Davenport DL: Association of blood transfusion and venous thromboembolism after colorectal cancer resection. Thromb Res 129:568-572, 2012

54. Zairi F, Arikat A, Allaoui M, Marinho P, Assaker R: Minimally invasive decompression and stabilization for the management of thoracolumbar spine metastasis. J Neurosurg Spine 17:19-23, 2012

\section{Author Contributions}

Conception and design: both authors. Acquisition of data: Lau. Analysis and interpretation of data: Lau. Drafting the article: Lau. Critically revising the article: both authors. Reviewed submitted version of manuscript: both authors. Approved the final version of the manuscript on behalf of both authors: Chou. Statistical analysis: Lau. Study supervision: Chou.

\section{Correspondence}

Dean Chou, Department of Neurological Surgery, University of California, San Francisco, 505 Parnassus Ave., Box 0112, San Francisco, CA 94143. email: choud@neurosurg.ucsf.edu. 